\title{
Introduction: Political economy
}

\author{
Esther Schüring
}

Designing a social protection system is of course not only a technical exercise but a very political affair. A systems approach to social protection is shaped by the political elites and the respective coalitions of change, the political institutions as well as the political system of a country. This explains why also seemingly similar countries in terms of their risk profile, poverty situation and economic situation can adopt very different social protection systems or make very different progress with respect to social protection expansion. Not only are the established welfare states of the Global North but also the nascent social protection systems in the Global South a testimony of this variety.

While most international actors have realized the importance of the political economy of social protection, international organizations have turned a blind eye to the fact that they are part of the political game. Chapter 29 on international actors and social protection by Seekings demonstrates that international organizations have tried to depoliticize their support, presenting themselves as technical experts. International actors have sold the expansion of social protection systems as technically sound and norm-wise appropriate, delegitimizing any possible skepticism that naturally arises when redistributive policies are at stake. Donors themselves cannot claim to have been purely technical in their approach either. While efforts were undertaken to harmonize approaches and appear united, ideological differences surfaced, in particular between the International Labour Organization's rights-based and the World Bank's needs-based approaches. International actors have been equally competing for ideas and it is also noticeable when looking at the design of social protection systems in different countries which agency and also which consultant was in the lead. This does not mean, however, that international actors have had unlimited power over social protection systems in low- and middle-income countries. They managed to place social protection on the political agenda but were much less powerful in convincing parliaments and government ministries to expand social protection to the degree they desired.

An area which has received less attention and has also been overlooked by international actors is public preferences for social protection, which are discussed in Chapter 30 by Bender. The initial focus was primarily to get social protection onto the political agenda and to worry less about public support for it. However, when it comes to sustaining reform efforts in social protection, it is important to understand redistributive preferences and the underlying factors. Individuals but also societies differ with respect to preferences, calling into question to what extent social protection systems can be standardized in the first place. Preferences depend on present and expected future income levels, social norms as well as the level of information that is provided about a particular policy but also the situation at hand that the policy is responding to. The respective weight of these factors varies and more research is needed to detect clear patterns. Further research needs to also critically look into how preferences are best measured and in what way preferences influence policy responses. One lesson to be learned is, however, that in order to increase the acceptability of social protection reforms, communication and policy framing seem critical. 
This is also demonstrated in Chapter 32 on the acceptability of social protection reforms by Timár, who illustrates with various country examples that reform communication can decide on the success or failure of a social protection reform. Next to this, it is important to identify and potentially compensate reform losers in a sensible manner. While reforms can take on many different forms, reform winners and losers are not so easily determined. This requires careful consideration of which costs and benefits are factored in and how gains and losses are valued. Whether a reform is successfully launched, depends on the political settlement as the case study on the political economy of non-take-up of the BIG in South Africa by Mathebula exemplifies. It takes just one dominant political player to not be in favor of the policy reform to destroy the reform initiative, even when a policy is deemed suitable in light of high inequality, unemployment, and the urge to extend coverage to the black majority and when favorable institutions such as a constitutional basis are in place.

There are of course other factors which have an influence on whether social protection is adopted. Niño-Zarazúa and Santillán Hernández discuss in Chapter 31 on the political economy of social protection adoption the role of democratization in influencing the expansion of social transfer schemes. Conducting empirical analysis, they conclude that in particular when it comes to the design of social transfer schemes, democratization matters, next to state capacity, tax structure and the demographic characteristics of voters. Not only formal but also informal institutions are important as the case study on the political economy of social protection in Kenya by Rohregger shows. Traditional authorities are important gate keepers in social protection programs; they have an inclusionary function due to the knowledge of their communities and the respect they enjoy but their involvement sometimes leads to exclusionary effects due to nepotism. It is therefore important to find a politically astute way of combining the formal and informal authorities. 